\title{
A tarefa da filosofia em Foucault: uma redefinição de filosofia?
}

Nuno Melim

"A filosofia, ao renunciar à sua grande tradição, permanece-lhe fiel." Habermas

\section{Em jeito de introdução: morte ou transfiguração da filosofia?}

Outrora, mas num tempo ainda não muito afastado de nós, adoptou-se um discurso como que apocaliptico, fúnebre, acerca da filosofia. Percebendo sinais de crise, e num tom talvez não muito choroso, alguns diziam "adeus à filosofia". A filosofía, no sentido da sua grande tradição, encontrava o seu fim.

Heidegger é testemunha desse fim quando afinma, justamente, que a ramificação ou disseminação da filosofia em ciências autónomas se constitui como o acabamento legítimo da filosofia ${ }^{2}$. Esta constatação, seguida da questão acerca da possibilidade de um outro pensar, não já filosófico e do qual Heidegger se despede ${ }^{3}$, faz ao mesmo tempo a «autópsia». Facilmente se detecta a causa do "falecimento»: demasiada exposição às ciências. Ciências em relação às quais a filosofia, por falta de diferenças, perdeu identidade, autonomia, especificidade. Além de acabar (com) a filosofia, o predomínio do pensar científico, técnico, indicia a pobreza de pensamento que caracteriza, segundo Heidegger, o nosso mundo ${ }^{4}$.

Essa crise não escapou ao olhar atento de Foucault. A propósito da profunda mutação na epistêmê ocidental do século XIX, refere, como um dos sinais dessa mudança, "a reflexão da filosofia sobre o seu próprio futuro". Reflexão que deverá surgir igualmente aquando de uma certa "impressão de acabamento e de fim" emergente na comunidade

1 Para um esclarecimento mais detalhado desta "despedida", cf. Habernas, "La redéfinition du rôle de la philosophie" in Moralbewusstsein und Kommunikatives Handeln. Morale et communication, trad. Christian Bouchindhomme, Paris, Flammarion, 1986, pp. 23-40.

2 Vide Heidegger, "Das Ende der Philosophie und die Aufgabe des Denkens". "La fin de la philosophic ét la tâche de la pensée" in Questions III et IV, trad. Jean Lauxerois et Claude Roëls, Paris, Gallimard, 2000, p. 285.

3 Vide Habermas, op. cit., p. 33.

4 Vide Heidegger, "Gelassenheit". "Sérénité" in Questions III et IV, trad. André P'réau, edição citada, p. 135. 
filosófica do século XX; quer dizer, a reflexão irrompe entre o acabar e a possibilidade, que abre, de outro começar'.

Tal como Heidegger, mas com apreciáveis diferenças, Foucault reconhece a ramificação ou disseminação da filosofia, as mudanças ocorridas no seu seio, detecta uma "perigosa", ainda que exagerada, "familiaridade" entre a filosofia e certas ciências ${ }^{6}$. Contudo, onde Heidegger deduz o acabamento da filosofia, Foucault percebe actividade filosófica em dispersão, e se um se inquieta com a pobreza do pensamento, o outro sofre, pelo contrário, com a sua abundância ${ }^{7}$.

A filosofia, no sentido da sua grande tradição, encontrava o seu fim, mas era possível que procurasse "pensar de outra maneira", que continuasse sem as características tradicionais - e sem precisar de dar o salto para um pensar "poético".

As ciências conduziram, inevitavelmente, a uma transformação ou acabamento da filosofia, mas não ao seu completo desaparecimento. Enquanto alguns pensaram escutar o canto do cisne da filosofia e trataram de se despedir, outros não se comprometeram com um tal adeus; quer dizer, tentaram redefinir ou "recomeçar" a filosofia. Era possível que, apesar da impressão de acabamento e de fim, qualquer coisa nova se desenhasse e entrevisse no horizonte ${ }^{8}$. Era bem possível que a filosofia sobrevivesse às suas carpideiras.

5 Vide Foucault, Les mots et les choses, Paris, Gallimard, 1966, p. 233 e p. 396. Uma filosofia acaba, mas não se rejeita a possibilidade de uma outra começar: "Si la découverte du Retour est bien la fin de la philosophie, la fin de l'homme, elle, est le retour du commencement de la philosophie" (Foucault, op. cit., p. 353).

6 Sobre a ramificação, cf. Foucault, "Philosophie et psychologie" in Dits et écrits I, Paris, Quarto/Gallimard, 2001, p. 467: "[...] maintenant les problèmes de la philosophie sont tous logés à l'intérieur de ce domaine que l'on peut appeler celui de la finitude humaine. Si l'on ne peut plus philosopher que sur l'homme en tant qu'il est un homo natura, ou encore en tant qu'il est un être fini, dans cette mesure-là, est-ce que toute philosophie ne sera pas, au fond, une anthropologie? À ce moment-là, la philosophie devient la forme culturelle à l'intérieur de laquelle toutes les sciences de l'homme en général sont possibles". Sobre a disseminação, cf. "Sur les façons d'écrire l'histoire" in Dits et écrits I, edição citada, p. 625: “[...] la philosophie aujourd'hui n'existe plus, non pas en ceci qu'elle aurait disparu, mais qu'elle s'est disséminée dans une grande quantité d'activités diverses: ainsi, les activités de l'axiomaticien, du linguiste, de l'ethnologue, de l'historien, du révolutionnaire, de l'homme politique peuvent être des formes d'activité philosophique". Sobre as mudanças, cf. "La philosophie structuraliste permet de diagnostiquer ce qu'est "aujourd'hui»" in Dits et écrits I, edição citada, p. 608: "[...] la philosophie s'est allégée de toute une série de recherches qui ont constitué les sciences humaines [...] a perdu son statut privilégié par rapport à la connaissance en géneral, et à la science en particulier. Elle a cessé de légiférer, de juger [...] d'être une spéculation autonome sur le monde, la connaissance ou l'être humain". Acerca da "perigosa familiaridade", cf. Les mots et les choses, edição citada, p. 359. As ciências humanas, decorrentes da "antropologização» - de raiz filosófica - do saber, são exemplo dessa perigosa familiaridade: animadas por uma "mobilidade (quase) transcendental", exercem um questionamento crítico face a si próprias (cf. Foucault, op. cit., p. 375).

7 "Non, je ne crois pas à la ritournelle de la décadence, de l'absence d'écrivains, de la stérilité de la pensée, de l'horizon bouché et morne. Je crois au contraire qu'il y a pléthore. Et que nous ne souffrons pas du vide, mais du trop de moyens pour penser tout ce qui se passe" (Foucault, "Le philosophe masqué" in Dits et écrits II, Paris, Quarto/Gallimard, 2001, p. 927).

8 “...] Et pourtant l'impression d'achèvement et de fin, le sentiment sourd qui porte, anime notre pensée, l'endort peut-être ainsi de la facilité de ses promesses, et qui nous fait croire que quelque chose de nouveau est en train de commencer dont on ne soupçonne qu'un trait léger de lumière au bas de l'horizon [...]". (Les mots et les choses, edição citada, p. 396). Habermas é exemplo desse esforço de redefinição. Depois da alienação do seu património e face ao seu glorioso passado, a filosofia, salienta Habermas, deve assumir 
Apesar de a filosofia se ter disperso em actividades díspares, Foucault admite a possibilidade de uma forma de filosofia ainda autónoma. Filosofia que se realiza não sem algumas nítidas diferenças em relação à sua tradição. Na esteira de Nietzsche, mais tarde remontada a Kant, diz que tal filosofia é definida pela actividade de diagnóstico, pela atenção ao presente ${ }^{9}$. Diagnosticar o presente é diagnosticar o estado do pensamento; característica a partir da qual, adianta Foucault, podemos considerar que há dois tipos de filósofos:

"[...] aquele que abre novos caminhos para o pensamento, como Heidegger, e aquele que assume, de algum modo, o papel de arqueólogo, que estuda o espaço no qual se desdobra o pensamento, assim como as condições desse pensamento, o seu modo de constituição"10.

$* * *$

Com esta já longa introdução, quisemos começar por mostrar que podemos encontrar no pensamento de Foucault uma resposta à questão «o que é a filosofia?». Dizemos que podemos encontrar uma resposta: essa resposta mais não é que a sua filosofia. Filosofia que se estabelece e se define em relação a uma "tradição" e ao que lhe é contemporâneo. Todavia, nesta introdução, referimo-nos à filosofia como se ela atravessasse incólume a história: $a$ filosofia, "filosofia perene". Ainda assim, não deixámos de notar filosofias. Seguindo Husserl, distinguimos a filosofia enquanto factum histórico de cada época e a filosofia enquanto ideia de uma tarefa infinita, ideia que tem a sua efectividade na história através de tentativas, mais ou menos felizes, de a realizar ${ }^{11}$. O problema é o da história $d a$ filosofia, que é história de filosofias. Problema com que deparamos se quisermos situar a filosofia de Foucault na história da filosofia, pois sabemos que Foucault rejeita qualquer fio condutor que percorra toda a história (o que,

um papel mais modesto no campo do saber. Não pode mais reivindicar um acesso privilegiado à verdade, mas pode assumir um papel de intérprete, de mediadora entre o saber dos especialistas e uma prática quotidiana em busca de orientação; desse modo, a filosofia pode fazer render tal saber e contribuir a uma tomada de consciência das deformações que afectam o mundo vivido (cf. Habermas, "Retour à la métaphysique?" in Nachmetaphysisches Denken: Philosophische Aufsätze. La pensée postmétaphysique: Essais philosophiques, trad. Rainer Rochlitz, Paris, Armand Colin, 1993, p. 60). No entanto, esta redefinição não confere autonomia à filosofia; é uma versão "fraca» de filosofia: já não lhe compete a produção de saber, apenas a sua reprodução. Foucault rejeita este papel de intérprete em que a filosofia tem como função traduzir saber especializado em saber ad usum delphini, por assim dizer; «trocar por miúdos», e para «miúdos», o saber dos especialistas: "L'essai - qu'il faut entendre comme épreuve modificatrice de soi-même dans le jeu de la vérité et non comme appropriation simplificatrice d'autrui à des fins de communication - est le corps vivant de la philosophie [...]" (Foucault, Histoire de la sexualité II - L'usage des plaisirs, Paris, Gallimard, 1984, p. 16, itálico nosso).

"[...] s'il y a maintenant une activité autonome, s'il peut y avoir une philosophie qui ne soit pas simplement une sorte d'activité théorique intérieure aux mathématiques ou à la linguistique ou à l'ethnologie ou à l'économie politique, s'il y a une philosophie indépendante, libre de tous ces domaines, eh bien, on pourrait la définir de la manière suivante: une activité de diagnostic" ("Foucault répond à Sartre" in Dits et écrits $I$, edição citada, p. 693).

10 Foucault, “qu'est-ce qu'un philosophe?" in Dits et écrits I, edição citada, p. 581.

1 Vide Husserl, "La crise de l'humanité et la philosophie" in Die Krisis der Europaischen Wissenschaften und die Transzendentale Phaenomenologie. La crise des sciences européennes et la phénoménologie transcendentale, trad. Gérard Granel, Paris, Gallimard, 1999, pp. 372-373. 
certamente, vale também para a história da filosofia). Fiéis ao desbarato, lendo foucauldianamente Foucault, deveríamos abordar a sua filosofia como factum histórico, não a enquadrando no sentido "teleológico" da história da filosofia especificado por Husserl. Contudo, é possível considerar a sua ascendência mais próxima, a sua "proveniência".

Neste estudo, não exaustivo, procuraremos introduzir-nos no pensamento de Foucault, considerando-o no horizonte aberto pela questão «o que é a filosofia?». Pretendemos averiguar o que entende Foucault por «filosofia». Avançámos já em esquisso a sua resposta; no que se segue, tentaremos, grosso modo, esclarecer essa filosofia enquanto filosofia crítica, considerar qual a sua possível tarefa, salientar alguns aspectos da arqueologia e da genealogia enquanto componentes de tal filosofia.

\section{Uma complicada filosofia crítica: a arqueologia e a genealogia}

Comummente, distinguem-se três momentos no pensamento de Foucault: um período arqueológico que considera sistemas de saber e as formações discursivas que os articulam, um período genealógico que considera modalidades ou relações de poder e um período ético que incide sobre a subjectividade, a construção do sujeito. Três etapas de uma filosofia que são regidas por uma unidade ou, pelo menos, por uma tentativa de unidade. Poderá parecer estranho que um pensador, que tanto se esforçou por defender a noção de descontinuidade, de transformação, tenha igualmente procurado, por diversas vezes, unificar a sua démarche filosófica através do que poderíamos designar «unificações retrospectivas». Em nosso entender, a unidade do percurso transparece como tentativa de filosofia crítica herdada de Kant. O posicionamento na "dinastia" filosófica aberta por Kant é, aliás, reconhecido pelo próprio Foucault: "Se Foucault se inscreve na tradição filosófica, é na tradição crítica de Kant e poderíamos designar o seu empreendimento de história crítica do pensamento"l2.

A história crítica do pensamento, acrescenta Foucault nesse mesmo texto, é, à semelhança da filosofia crítica kantiana, uma análise de condições. A análise de condições é constante ao longo do seu trajecto filosófico. No seu todo, a história crítica do pensamento, dirá Deleuze, é história das condições a partir das quais se manifesta o saber, história das condições a partir das quais se integram relações de forças (poder), história das condições a partir das quais a relação a si se constitui (subjectividade); sendo o saber, o poder e o si a tripla raiz de uma problematização do pensamento ${ }^{13}$.

Filosofia crítica herdada de Kant, mas revista, transformada: renúncia $e$ fidelidade.

12 Foucault, "Foucault" in Dits et écrits II, edição citada, p. 1450. Já em Les mots et les choses encontramos várias referências a esta herança: "notre pensée aujourd'hui appartient encore à leur dynastie" (edição citada, p. 256), "la pensée qui nous est contemporaine et avec laquelle, bon gré mal gré, nous pensons [...] cette pensée formée au seuil de l'âge moderne, vient encore jusqu'à nous, nous investit, et sert de sol continu à notre discours" (p. 262), "la pensée de la finitude que la critique kantienne a prescrite comme tâche à la philosophie, tout ceci forme encore l'espace immédiat de notre réflexion. Nous pensons en ce lieu" (p. 396). Para uma discussão das problemáticas "unificações retrospectivas" e da relação entre Foucault e Kant, vejam-se, por exemplo, o estudo de Béatrice Han, L'ontologie manquée de Michel Foucault, Grenoble, Éditions Jérôme Millon, 1998 e o de David Owen, Maturity and modernity: Nietzsche, Weber, Foucault and the ambivalence of reason, London and New York, Routledge, 1994, pp. 140-213.

13 Vide Deleuze, Foucault, Paris, Les Éditions de Minuit, 1991, p. 124. As obras do período arqueológico não deixam de enfatizar este aspecto crítico e, a par, 'a aproximação a Kant: "Les analyses précédentes [...] ont montré les formes d'apparition de la maladie, elles 


\section{A arqueologia}

A arqueologia assume-se como pesquisa histórica $e$ filosófica das condições do saber. Se há algo que Foucault procura pensar, algo incontornável para o seu pensamento, é precisamente a história. Parafraseando Heidegger, diríamos que a questão de saber se, como e dentro de que limites é possível pensar filosoficamente a história - do pensamento - tornou-se e permaneceu para Foucault o aguilhão, não secreto, que desencadeou o seu próprio pensamento: "Modo de ser de tudo o que nos é dado na experiência, a história tornou-se o incontornável do nosso pensamento"14.

A pesquisa é situada no campo da história e de acordo com uma certa metodologia. A arqueologia procura pensar a transformação histórica, não considera "a grande calma razoável da história", o seu plácido "devir horizontal", não se orienta por uma "teleologia da verdade" ou pela ideia de "progresso": o problema não é o de um fundamento que se perpetua, é o de transformações que valem como fundamentação e renovação de fundamentações ${ }^{15}$.

n'ont pas pu en démontrer les conditions d'apparition. [...] L'aliénation, avec ce contenu nouveau, n'est plus une aberration psychologique, elle est définie par un moment historique: c'est en lui seulement qu'elle est rendue possible" (Maladie mentale et personnalité, Paris, Presses Universitaires de France, 1954, p. 71. e p. 102); "En realité, c'est dans l'histoire seulement que l'on peut découvrir le seul a priori concret, où la maladie mentale prend, avec l'ouverture vide de sa possibilité, ses figures nécessaires" (Maladie mentale et psychologie, Paris, Quadrige/ Presses Universitaires de France, 1997, p. 101); "La recherche ici entreprise implique donc le projet délibéré d'être à la fois historique et critique, dans la mesure où il s'agit, hors de toute intention prescriptive, de déterminer les conditions de possibilité de l'expérience médicale [...] Ici, comme ailleurs, il s'agit d'une étude qui essaie de dégager dans l'épaisseur du discours les conditions de son histoire" (Naissance de la clinique, Paris, Quadrige/ Presses Universitaires de France, 2000 , p. xv.); “[...] c'est plutôt une étude qui s'efforce de retrouver à partir de quoi connaissances et théories ont été possibles; selon quel espace d'ordre s'est constitué le savoir; sur fond de quel a priori historique et dans l'élément de quelle positivité des idées ont pu apparaître [...]" (Les mots et les choses, edição citada, p. 13); L'ordre du discours, obra que faz a transição para a genealogia, enquanto complementando a arqueologia, explicitará: "[...] à partir du discours lui-même, de son apparition et de sa regularité, aller vers ses conditions externes de possibilité" (L'ordre du discours, Paris, Gallimard, 1971, p. 55).

14 Foucault, Les mots et les choses, edição citada, p. 231. Neste sentido, a arqueologia é "filha do seu tempo": "La philosophie au XIX" siècle se logera dans la distance de l'histoire à l'Histoire, des événements à l'Origine, de l'évolution au premier déchirement de la source, de l'oubli au Retour. Elle ne sera donc plus Métaphysique que dans la mesure où elle sera Mémoire, et nécessairement elle reconduira la pensée à la question de savoir ce que c'est pour la pensée d'avoir une histoire. [...] N'y voyons pas la fin d'une réflexion philosophique autonome, trop matinale et trop fière pour se pencher, exclusivement, sur ce qui fut dit avant elle et par d'autres; n'en prenons pas prétexte pour dénoncer une pensée impuissante à se tenir toute seule debout, et toujours contrainte à s'enrouler sur une pensée déjà accomplie. Qu'il suffise de reconnaître là une philosophie, déprise d'une certaine métaphysique parce que dégagée de l'espace de l'ordre, mais vouée au Temps, à son flux, à ses retours parce que prise dans le mode d'être de l'Histoire" (Les mots et les choses, edição citada, pp. 231 -232., itálico nosso). A questão da história é realçada logo nos primeiros textos de Foucault: "Les formes originales de pensée s'introduisent elles-mêmes: leur histoire est la seule forme d'exégèse qu'elles supportent, et leur destin, la seule forme de critique" ("Introduction" in Dits et écrits I, edição citada, p. 93; veja-se também o trecho supracitado de Maladie mentale et personnalité; ambos os textos datam de 1954, o ano de "estreia»).

15 Vide "Préface" in Dits et écrits I, edição citada, p. 189 ss. e Foucault, L'archéologie du savoir, Paris, Gallimard, 1969, p. 12. 
Para pensar criticamente a história e a fim de esclarecer o seu método e domínio de análise, de "definir o seu espaço singular pela exterioridade das suas vizinhas", de se demarcar de outras investigações, a arqueologia, em jeito fenomenológico, cumpre certas exigências de método, começa por uma «redução arqueológica» ${ }^{16}$.

Exemplo ilustre, com a sua dose de polémica, é a recusa do "sujeito transcendental". A certo momento, pergunta-se: “[...] será que um sujeito de tipo fenomenológico, trans-histórico, é capaz de dar conta da historicidade da razão?"17.

Arqueologia e fenomenologia movem-se em sentidos opostos. A história não interessa a uma fenomenologia pura: os factos históricos são "transcendentes". A fenomenologia suspende o histórico, enquanto contingente e relativo, a caminho do "resíduo fenomenológico", do que é dado com evidência apodíctica e necessariamente em jogo: o eu puro ${ }^{18}$. Embarcando numa fenomenologia deste tipo, retrocedemos ante a história e criamos um fosso dificilmente transponível. Colocado de um modo simples, o problema para Foucault seria: se partimos de um tal sujeito, fechado na sua "imanência", na sua "pureza", como chegamos à história considerada como "transcendência", como damos conta da sua "impureza"?

Foucault, poder-se-á dizer, reduz a «imanência». É na história que se move e é a história que procura pensar. Não é para o sujeito transcendental que se dirige, nem toma este como ponto de partida. Em relação a Kant, digamos que efectua um estudo das condições da "experiência", sem analisar as faculdades de um sujeito que se vê na posse de algo "em que se verifica absoluta independência de toda e qualquer experiência". O sujeito não é transcendente à história, é histórico, não «causa», mas «efeito», não «substância», mas «acidente»:

16 Vide Foucault, op. cit., p. 31 ss. Todo um conjunto de noções e temas (certas "unidades discursivas") são colocados «entre parêntesis»: "tradição», «influência», "desenvolvimento», "evolução», "mentalidade», "espírito», "géneros de discurso», «livro», "obra», "autor», "origem secreta e inalcançável», o "discurso latente do discurso manifesto", etc. Falamos de uma "redução arqueológica" porque L 'archéologie du savoir é atravessada por expressões decalcadas, maliciosamente talvez, da fenomenologia, por exemplo: "mettre en suspens" (p. 33, p. 37), "mettre hors circuit" (p. 36), "Il faut une certaine conversion du regard et de l'attitude pour pouvoir le reconnaître et l'envisager en lui-même" (p. 145). A malícia consiste no facto de a "redução arqueológica» suspender, em certo sentido, a "redução fenomenológica».

17 Foucault, "Structuralisme et poststructuralisme" in Dits et écrits II, edição citada, p. 1255. Foucault insistiu, diversas vezes, nesta recusa: “[...] affranchir l'histoire de la pensée de sa sujétion transcendantal [...] la dépouiller de tout narcissisme transcendantal [...] libérer l'histoire de l'emprise phénoménologique [...]" (L'archéologie du savoir, edição citada, pp. 264-265). Devemos notar, todavia, que o sujeito não é completamente elidido a favor de uma pura objectividade. O que se pretende é analisar os processos próprios a uma experiência em que o sujeito e o objecto se formam e transformam um em relação e em função do outro (cf. "Foucault" in Dits et écrits II, edição citada, p. 1453). O que se contesta é a «soberania» do sujeito, não o sujeito enquanto «problema»: “[...] bref, j'ai voulu non pas exclure le problème du sujet, j'ai voulu définir les positions et les fonctions que le sujet pouvait occuper dans la diversité des discours" (L'archéologie du savoir, edição citada, p. 261).

18 Aludimos, evidentemente, ao Husserl das Ideen I; cf. Husserl, Ideen zu einer Reinen Phaenomenologie und Phaenomenologischen Philosophie. Idées directrices pour une phénoménologie et une philosophie phénoménologique pures, trad. Paul Ricoeur, Paris, Gallimard, 1989, § 56 a $\S 62$. Não ignoramos a possibilidade de uma "fenomenologia histórica"; Husserl pensá-la-á noutros textos. Mas a arqueologia de Foucault distingue-se quer da "fenomenologia pura", quer de uma "fenomenologia histórica", que não deixa de estar problematicamente articulada com a primeira (cf. L'archéologie du savoir, edição citada, p. 265). 


\begin{abstract}
"Podemos dizer que toda a civilização ocidental foi sujeitada [assujettie] e os filósofos, ao referirem todo o pensamento e toda a verdade à consciência, ao Eu, ao Sujeito, não fizeram senão estabelecer um tal processo. No estrondo que nos abala hoje, é preciso reconhecer talvez o nascimento de um mundo em que se sabe que o sujeito não é uno, mas cindido, não soberano, mas dependente, não origem absoluta, mas função incessantemente modificável"19.
\end{abstract}

O acesso à história é garantido por outro meio. Em Foucault, falamos de discurso, de um discurso que não é "representação". Discurso tomado como evento, como algo que "se mostra em si mesmo e a partir de si mesmo", monumento a descrever intrinsecamente: "não há nada por detrás do discurso"20.

A pesquisa das condições do saber é situada no campo da história e ao nível do discurso. Segundo $L$ 'archéologie du savoir, é esse o «resíduo arqueológico: o domínio constituído pelo conjunto de todos os enunciados na sua dispersão de eventos, uma população de eventos no espaço do discurso em geral. O que se pretende é elaborar uma descrição neutra dos eventos discursivos, analisar as condições da experiência discursiva efectiva, considerar as condições históricas de possibilidade internas ao saber, não ignorando, no entanto, as relações do saber com o extradiscursivo ${ }^{21}$.

A arqueologia analisa formações discursivas, espaços de dispersão de enunciados nos quais detecta e define regularidades enunciativas, regras de formação, condições de aparecimento histórico ${ }^{22}$. Os discursos são considerados enquanto práticas que obedecem a regras e analisar as regras de formação dos discursos é estabelecer o tipo de positividade que os caracteriza. Por exemplo, o conhecimento produzido pela psiquiatria, no início do século XIX, foi possível devido a regras de formação próprias a tal disciplina, mas também devido ao jogo de relações entre a hospitalização, o internamento, as condições e os procedimentos da exclusão social, as regras da

19 Foucault, "La naissance d'un monde" in Dits et écrits I, edição citada, p. 817.

20 Sobre o documento considerado enquanto monumento, cf. L'archéologie du savoir, edição citada, p. 13 ss.

21 Cf. L'archéologie du savoir, edição citada, pp. 38-39. Notemos duas coisas. Primeiro, a análise do discursivo não sai fora do âmbito da filosofia que diagnostica o presente: "Je veux concentrer mon étude sur ce qui nous arrive aujourd'hui [...] il y a, dans notre société et dans ce que nous sommes, une dimension historique profonde [...] Nous sommes inextricablement liés aux événements discursifs. En un sens, nous ne sommes rien d'autre que ce qui a été dit, il y a des siècles, des mois, des semaines..." ("Dialogue sur le pouvoir" in Dits et écrits II, edição citada, p. 469, itálico nosso). Segundo, o que se intenta estudar especificamente no período arqueológico é o discurso na sua autonomia, as "condições internas de possibilidade". do discurso; intenção que é patente no seguinte passo: "[...] dans l'historicité du savoir, ce qui compte, ce ne sont pas les opinions, ni les ressemblances qu'à travers les âges on peut établir entre elles [...] ce qui est important, ce qui permet d'articuler en elle-même l'histoire de la pensée, ce sont ses conditions internes de possibilité" (Les mots et les choses, edição citada, pp. 287-288). Contudo, o estudo da autonomia não construirá um foșso entre o discurso e o que não é discurso; não se pretende isolar o discurso na pureza da sua "imanência": "Faire apparaître dans sa pureté l'espace où se déploient les événements discursifs, ce n'est pas entreprendre de le rétablir dans un isolement que rien ne saurait surmonter; ce n'est pas le refermer sur lui-même; c'est se rendre libre pour décrire en lui et hors de lui des jeux de relations"( L'archéologie du savoir, edição citada, p. 41; sobre estas relações, veja-se também pp. 61-62). Ainda que a primazia seja dada ao discursivo, a descrição do jogo de relações entre o discursivo e o extradiscursivo é feita já, grosso modo, em Histoire de la folie e em Naissance de la clinique. 
jurisprudência, as normas do trabalho industrial e da moral burguesa; em suma, devido a todo um conjunto, a uma prática discursiva, que possibilita a formação dos seus enunciados. A prática discursiva não se manifesta, portanto, apenas numa disciplina com estatuto científico, encontra-se também em textos jurídicos, em expressões literárias, em reflexões filosóficas, em decisões de ordem política, etc. A formação discursiva, a positividade, que o estudo da psiquiatria permite assinalar não lhe é coextensiva: essa disciplina é um nó entre os nós de uma rede. Os elementos formados por uma prática discursiva permitem que algo como um discurso científico possa eventualmente constituir-se. O saber, a que a arqueologia se dedica especificamente, define-se como o conjunto de elementos formados de maneira regular por uma prática discursiva, elementos indispensáveis à constituição de uma ciência, mas não necessariamente destinados a dar-lhe lugar. Não há saber sem uma prática discursiva e toda a prática discursiva se pode definir pelo saber que ela forma ${ }^{23}$.

O estudo das positividades, a análise das relações entre os elementos da prática discursiva, permite descobrir um princípio de ordenação histórica anterior à ordenação estabelecida pelos critérios de cientificidade e dela independente. Investigando domínios diferentes, saberes diferentes, a arqueologia relaciona estes saberes, procura semelhanças que permitam esboçar a configuração geral do saber numa mesma época e diferenças que permitam distinguir configurações entre épocas (diferentes). A positividade funciona como "a priori histórico" e o sistema de enunciados produzido por diferentes positividades, segundo a priori históricos, é o arquivo ${ }^{24}$. A arqueologia é "descrição do arquivo", do a priori histórico geral.

Dissemos que a pesquisa arqueológica era histórica $e$ crítica. A conjunção é "um pouco aberrante": denota uma dificuldade. Numa perspectiva tradicional, a crítica apura isso que vale como a priori: as condições pensadas quanto à universalidade e necessidade; ou seja, o que está para além da história, enquanto esta é palco do empírico, do particular, do contingente. No entanto, a arqueologia investiga um a priori peculiar: um a priori histórico, um a priori empírico ${ }^{25}$.

O a priori foucauldiano, nos antípodas do a priori histórico de Husserl e do a priori kantiano, é um princípio de determinação não-subjectivo que define, num período e numa área geográfica dados, a forma histórica da constituição dos saberes. Não é uma

A este propósito, cf. L'archéologie du savoir, edição citada, pp. 233-234, pp. 237 ss.

24 Cf. L'archéologie du savoir, edição citada, pp. 166-173, p. 237 ss. O arquivo pode ser entendido como sistema geral: "A toutes les époques, la façon dont les gens réfléchissent, écrivent, jugent, parlent [...] et même la façon dont les gens éprouvent les choses, dont leur sensibilité réagit, toute leur conduite est commandée par une structure théorique, un système, qui change avec les âges et les sociétés - mais qui est présent à tous les âges et dans toutes les sociétés. [...] La tâche de la philosophie [...] c'est de mettre au jour cette pensée d'avant la pensée, ce sistème d'avant tout système..." (Foucault, "Entretien avec Madeleine Chapsal" in Dits et écrits I, edição citada, p. 543). Devemos salientar, todavia, que esta nossa tão linear apresentação salta, por economia, toda uma série de dificuldades. De facto, as noções de a priori histórico e epistêmê são redefinidas em L'archéologie du savoir: colidem com o que é apresentado em Les mots et les choses e em Naissance de la clinique a seu respeito. O funcionamento da rede de conceitos do período arqueológico "não escapa à historicidade": transforma-se.

25 Como indica Béatrice Han, a noção "a priori histórico" não é criada por Foucault, mas por Husserl (cf. op. cit., p. 110). Em Ursprung der Geometrie Husserl refere um a priori histórico que é, no fundo, supra-histórico, pois visa essencialmente garantir a possibilidade de desvelar, para lá das sedimentações ligadas à história e à tradição, as evidências primeiras originalmente tematizadas por "protofundadores» (cf. Husserl, "Ursprung der Geometrie" "L'origine de la géometrie", trad. Jacques Derrida, in Die Krisis der Europaischen Wissenschaften und die Transzendentale Phaenomenologie, edição citada, p. 418 ss). 
estrutura universal invariante, é uma estrutura histórica variável, sofre transformações que a arqueologia deve assinalar. Define-se como o conjunto das regras que caracterizam uma prática discursiva numa determinada época, deve dar conta de que o discurso tem uma história e não escapa ele mesmo à historicidade. As regras não se impõem do exterior aos elementos que colocam em relação, estão investidas nisso mesmo que regulam; modificam esses elementos e transformam-se com eles. Face ao a priori formal, é empírico: é dado na história e transforma-se com ela. Não é uma grande figura imóvel e vazia ao longo de toda a história ou um "transcendental sincopado": é solidário com o que gera ${ }^{26}$. E o chamado positivismo de Foucault.

Só há práticas, positividades, que são constitutivas do saber e dadas historicamente. A pesquisa arqueológica incide sobre um a priori concreto, local, contingente, provisório, não sobre um a priori absolutamente independente da experiência, formal, universal, necessário: o seu a priori não é «puro». A filosofia crítica de Foucault não é fillosofia transcendental:

"Enfim, vê-se que a análise da epistêmê não é uma maneira de retomar a questão crítica [...] No enigma do discurso científico, o que ela questiona não é o seu direito a ser uma ciência, é o facto de ele existir. $\mathrm{O}$ ponto pelo qual ela se separa de todas as filosofias do conhecimento é o não relacionar esse facto à instância de uma doação originária que fundaria, no sujeito transcendental, o facto e o direito, mas aos processos de uma prática histórica"27.

$* * *$

Com a busca de condições, do nível fundante, notamos a afinidade com Kant. Todavia, as condições procuradas e esclarecidas são as da experiência real, efectiva, não as da experiência possível, estão do lado do «objecto», da prática histórica, não de um sujeito universal ou transcendental.

A abordagem arqueológica tem, evidentemente, os seus problemas. Um deles é a confusão entre o empírico e o transcendental, denunciada em Les mots et les choses, mas patente na noção de "a priori histórico": as condições parecem ser assimiladas ao que condicionam. Outro problema é a oscilação entre uma teoria descritiva, neutra, de bizarras práticas discursivas auto-regidas, e uma teoria prescritiva do discurso ${ }^{28}$.

Contudo, o positivismo ainda que dificil e não tão "feliz" quanto Foucault o deseje, não é ingénuo: é «semicrítico». Como salienta o próprio Foucault, a arqueologia não é completamente crítica face a si mesma:

“[...] não nos é possível descrever o nosso próprio arquivo, pois é no interior das suas regras que falamos [...] $\mathrm{O}$ arquivo não pode ser descrito na sua totalidade [...] como

Sobre o a priori histórico, cf. L'archéologie du savoir, edição citada, pp. 167-169.

Foucault, op. cit., p. 251.

Essa confusão mostra a arqueologia como «filha do seu tempo»; os passos seguintes, não destinados a descrever a arqueologia, podem, no entanto, ser aplicados ao seu positivismo: "Il y a aussi les analyses qui [...] on montrait [...] qu'il y avait une histoire de la connaissance humaine, qui pouvait à la fois être donné au savoir empirique et lui prescrire ses formes. [...] elles peuvent se dispenser de tout recours à une analytique (ou à une theorie du sujet): elles prétendent pouvoir ne reposer que sur elles-mêmes, puisque ce sont les contenus eux-mêmes qui fonctionnent comme réflexion transcendentale" (Les mots et les choses, edição citada, p. 330). Para uma análise detalhada destes problemas, cf. Dreyfus, H. L., Rabinow, P. , Michel Foucault: beyond structuralism and hermeneutics. Michel Foucault: un parcours philosophique, trad. Fabienne Durand-Bogaert, Paris, Gallimard, 1984, pp. 119-147. 
poderá a descrição do arquivo justificar-se [...] se teima em descrever apenas os horizontes mais longínquos? Não será preciso aproximá-la da positividade a que ela mesma obedece? [...] A análise do arquivo comporta uma região privilegiada: simultaneamente próxima de nós e diferente da nossa actualidade [...] é o que, fora de nós, nos delimita. A descrição do arquivo desdobra as suas possibilidades [...] a partir dos discursos que deixam de ser, justamente, os nossos; o seu limiar de existência é instaurado pelo corte que nos separa disso que não mais podemos dizer e disso que está fora da nossa prática discursiva; [...] Nesse sentido, ela vale para o nosso diagnóstico"29.

O lugar da arqueologia é a diferença do nosso presente: ela estabelece a diferença do nosso presente quando exuma o seu subsolo. Detecta diferenças, mudanças; nota que, agora, a nossa razão é a diferença dos discursos, a nossa história a diferença dos tempos, o nosso eu a diferença das máscaras, e que a diferença, longe de ser origem esquecida e descoberta, é a dispersão que somos e que fazemos ${ }^{30}$.

A dificuldade da descrição completa do arquivo, do a priori histórico ou da

epistêmê é salientada já em Les mots et les choses ${ }^{31}$. A arqueologia descreve monumentos, monumentos cuja totalidade só é visível à distância: só lhe é possível analisar uma epistêmê quando está para além dela. É possível descrever a epistêmê clássica, já acabada, mas não a moderna, que possibilita historicamente a própria arqueologia e cuja disposição fundamental é a antropologia:

"Essa disposição é essencial porque faz parte da nossa história, mas está a desfazer-se sob o nosso olhar, uma vez que começamos a reconhecer, a denunciar de um modo crítico, o esquecimento da abertura que a tornou possível e o obstáculo teimoso que se opõe a um pensamento próximo"32.

A arqueologia está na fronteira entre o passado e o futuro: no presente. O seu limiar de existência é o da epistêmê moderna que começa a desfazer-se no presente em favor de um "pensamento próximo". A arqueologia detecta a agonia da epistêmê moderna que a possibilita e esboça já algumas das suas características. O que significa que, de certo modo, está já para lá, mas não completamente para lá, da "analítica da finitude" ("simultaneamente próxima e distinta da actualidade" da arqueologia). O que anuncia é o fim próximo da epistêmê, a possibilidade de uma outra, e, com isso, a possibilidade de uma descrição exaustiva da sua própria epistêmê. A arqueologia está alojada no interstício ou, brincando um pouco com a palavra, no inter-dito. É uma filha "ingrata" e "ilegítima" do seu tempo: apanhada ainda na abertura da sua epistêmê, que não suporta, mas de que não pode prescindir, a arqueologia nota já indícios de acabamento, transformação e, quem sabe?, talvez a proximidade do seu próprio fim. É que tudo se passa como se Foucault esteja apenas à espera que a contracapa do livro se abata sobre si; quer dizer, que a epistêmê se feche, que acordemos do "sono antropológico".

29 Foucault, L'archéologie du savoir, edição citada, pp. 171-172. Como se depreende facilmente, este "é no interior das suas regras que falamos" não combina com a pretensa neutralidade da análise arqueológica.

30 Vide Foucault, op. cit., p. 173.

31 "Et il a bien fallu un événement fondamental - un des plus radicaux sans doute qui soit arrivé à la culture occidentale pour que se défasse la positivité du savoir classique, et que se constitue une positivité dont nous ne sommes sans doute pas entièrement sortis. Cet événement, sans doute parce que nous sommes pris encore dans son ouverture, nous échappe pour une grande part" (Les mots et les choses, edição citada, p. 232).

32 Foucault, op. cit., p. 353, itálico nosso. 
Só então seria possível uma arqueologia da arqueologia: um análise mais detalhada das condições de possibilidade históricas da arqueologia. Mas nada garante que, com a nova disposição do saber, a arqueologia subsista: ou acaba com a epistêmê (que acaba) ou se transforma. O que notamos é a complicada situação histórica da própria arqueologia.

Ao ser incapaz de esclarecer adequadamente a sua situação no presente, de "determinar o lugar de onde fala, evitando o solo onde poderia tomar apoio", a arqueologia aproxima-se até do pensamento hermenêutico. A arqueologia é relativamente cega face ao seu presente, ao que lhe é mais próximo: "descreve os horizontes mais longínquos". Digamos que a incapacidade de analisar completamente o seu próprio a priori histórico é o preço a pagar por "um pensamento histórico que deve incluir o pensamento da sua própria historicidade" 33 .

Por outro lado, também porque de algum modo próxima da fenomenologia enquanto descrição (discutivelmente) neutra, a cegueira arqueológica face ao presente pode ser entendida como "metodológica". Tomemos um exemplo. A arqueologia, apesar de céptica em relação a uma verdade absoluta, não neutraliza inteiramente a questão da verdade. Não parte da verdade como critério de avaliação do passado do saber, mas procura defini-la no interior do próprio saber da época estudada; quer dizer, independentemente do saber da actualidade, é a própria época que define os seus critérios de verdade cujo fundamento é o a priori histórico que lhe é próprio. Com este procedimento, a arqueologia neutraliza, em parte, o seu próprio presente: não há "fusão de horizontes". O arqueólogo corta a história, não estabelece uma unidade entre o passado e o presente, quer assinalar a diferença do presente em relação ao passado.

Nem completamente ancorada no seu a priori histórico, nem no presente, a arqueologia parece andar à deriva. Se, por um lado, a arqueologia não é completamente crítica, por outro, não é completamente "pré-crítica", uma vez que questiona já algumas das suas condições de possibilidade. O seu positivismo é problemático, mas não é "escatológico", é «sem promessas» ${ }^{34}$. Não é naïf, sabe que está "no dorso de um tigre".

Apesar de tudo, o que importa destacar é que a arqueologia não é completamente crítica: nem em relação às condições de possibilidade internas ao saber, à positividade a que pertence, nem em relação às condições de possibilidade externas ao saber. Pois se pode analisar algumas das primeiras, não pode, em rigor, analisar nenhuma das segundas, porquanto estão para lá do seu domínio e método de análise. Para melhor se justificar, é necessária uma «viragem».

33 Vide Foucault, op. cit., p. 267. Como se sabe, a hermenêutica enfatiza precisamente a impossibilidade da explicitação integral da nossa situação histórica: "[...] on se trouve toujours impliqué dans une situation que l'on ne pourra jamais entièrement tirer au clair. Ce qui est également vrai de la situation herméneutique [...] cette impossibilité [...] s'inscrit dans l'essence de l'être historique que nous sommes. "Etre historique» signifie ne jamais pouvoir se résoudre en savoir de soi-même" (Gadamer, Hans-George, Wahrheit und Methode. Vérité et méthode, trad. Pierre Fruchon, Jean Grondin et Gilbert Merlio, Paris, Éditions du Seuil, 1996, pp. 323-324).

34 " [...] elle vaut pour notre diagnostic. Non point parce qu'elle nous permettrait de faire le tableau de nos traits distinctifs et d'esquisser par avance la figure que nous aurons à l'avenir. Mais elle nous déprend de nos continuités; elle dissipe cette identité temporelle où nous aimons nous regarder nous-mêmes pour conjurer les ruptures de l'histoire; elle brise le fil des téléologies transcendantales; et là où la pensée anthropologique interrogeait l'être de l'homme ou sa subjectivité, elle fait éclater l'autre et le dehors" (L'archéologie du savoir, edição citada, p. 172). Acerca do positivismo escatológico, ingenuamente pré-crítico, cf. Les mots et les choses, edição citada, p. 331. 


\section{Agenealogia}

Com a genealogia, a filosofia de Foucault deixa de perambular no adro de Kant: migra para a vizinhança da ermida de Nietzsche. Se a arqueologia é análise das condições históricas de possibilidade do saber, do discurso, a genealogia é análise das condições políticas de possibilidade, também históricas, do saber. Apesar de o aspecto crítico se manter, o tipo de questão metodológica muda: como é que através da análise do poder podemos explicar a produção dos saberes? A análise centra-se na correlação entre poder e saber.

Infelizmente, não dispomos de uma obra consagrada exclusivamente ao esclarecimento do modus operandi da genealogia. Para caracterizar a genealogia, o melhor ponto de partida será considerar o texto Nietzsche, la généalogie, l'histoire; texto que desenha a genealogia nietzschiana com traços não surpreendentemente semelhantes aos da arqueologia. Por exemplo, afirma-se que a genealogia pretende esclarecer a singularidade dos acontecimentos sem se referir a qualquer "finalidade monótona", opondo-se ao "desdobramento meta-histórico de significações ideais", a "teleologias indefinidas", e demarcando-se de qualquer "investigação da origem" 35 .

A "investigação da origem" tenciona recolher a essência exacta das coisas, algo anterior ao que é externo, acidental, sucessivo; procura desvelar uma identidade primeira. A origem é considerada como solene, como o momento da perfeição das coisas, como "anterior à queda", como o lugar da verdade. Todavia, o genealogistà insurge-se contra os "preconceitos" da origem, escuta a história, não a metafísica. Aprende que "o único sentido oculto das coisas é elas não terem sentido oculto nenhum", que são sem "essência" ou que a sua essência foi construída a partir de figuras que lhe eram estranhas. O que se encontra no começo histórico das coisas não é a identidade ainda preservada da sua origem, mas a discórdia com outras coisas. O começo histórico é baixo, reles, irrisório, sem pompa nem banda filarmónica ${ }^{36}$.

O genealogista estuda a proveniência e esse estudo permite desembrulhar toda uma rede de diferenças: não procura uma síntese vazia, antes o começo multifacetado. Sob o aspecto único de um carácter ou de um conceito, encontra a proliferação de eventos através dos quais se formaram tais conceitos ou caracteres. A sua tarefa não é mostrar que o passado está vivo no presente ou que o anima secretamente: é manter o passado na dispersão que lhe é própria, descobrir que na raiz do que conhecemos e somos não há absolutamente $a$ verdade, $o$ ser, mas o acidente, o acaso. A investigação da proveniência não pretende fundamentar, reencontrar as raízes da nossa identidade ou o centro único de onde provimos, pretende inquietar, mostrar os sistemas heterogéneos que nos regem. O genealogista estuda a emergência, os eventos produzidos sempre por relações de forças e suas transformações. A emergência é a

35 Vide "Nietzsche, la généalogie, l'histoire" in Dits et écrits I, edição citada, p. 1004. Este texto não fornece apenas pontos de continuidade entre a genealogia e a arqueologia, indicia também temáticas a que a genealogia propriamente foucauldiana prestará posteriormente atenção; por exemplo: "Nous pensons en tout cas que le corps, lui, n'a d'autres lois que celle de sa physiologie et qu'il échappe à l'histoire. Erreur à nouveau; il est pris dans une série de régimes qui le façonnent; [...] il se bâtit des résistances" (Foucault, op. cit., p. 1015). Em Surveiller et punir, Foucault estudará o corpo, não como cadáver aberto ao olhar do anatomista, a "noite viva que se dissipa na claridade da morte" abordada na arqueologia do olhar médico de Naissance de la clinique, mas enquanto apanhado num sistema de "sujeição", investido por relações de poder e dominação, na época em que emerge uma "economia política» do corpo (cf. Foucault, Surveiller et punir, Paris, Gallimard, 1975, pp. 33-34). A noção de «resistência» será igualmente crucial, como veremos.

36 Vide "Nietzsche, la généalogie, l'histoire", edição citada, pp. 1004-1007. 
entrada em cena das forças, designa um lugar de confronto. Face a uma história "supra-histórica", tradicional, povoada por absolutos, a genealogia opta por uma história "efectiva" (wirkliche Historie), sem constantes, não tenta dissolver o evento singular numa continuidade ideal. As forças em jogo na história não obedecem nem a uma destinação, nem a uma mecânica, mas ao acaso, à contingência persistente da luta:

"A história entorpece sob o olhar estóico do arqueólogo num icebergue
coberto de formas cristalinas de formações arbitrárias do discurso. [...]
Sob o olhar cinico do genealogista o icebergue põe-se em movimento:
as formações discursivas deslocam-se, misturam-se, sobem e descem.
O genealogista explica estas subidas e descidas com [...] a hipótese
segundo a qual a única coisa que perdura é o poder que volta sempre a
aparecer sob máscaras novas na mudança dos processos de subjugação" ${ }^{37}$.

$\mathrm{Na}$ aproximação a Nietzsche, o que importa destacar é que o começo do que se tem por racional, portador de verdade, é baixo, enraizado na dominação, nas relações de forças: no poder. Contudo, a migração para a genealogia não levou Foucault a adiantar uma teoria do poder. A análise não é regulada pela questão «o que é $o$ poder?», mas pela questão de «como se exerce». Antes de mais, o que se faz é uma analítica do poder. Analítica que não deixa de articular algumas regras gerais para o estudo do poder.

O poder é considerado ao nível das práticas reais, na sua «facticidade», no seu campo de aplicação; não é analisado nos seus mecanismos gerais, mas nas suas formas mais regionais e locais. A crítica tem um carácter local, não um carácter universal. Ainda assim, partindo desses mecanismos infinitesimais, que têm a sua história, tecnologia, táctica e solidez próprias, não deixa de ser preciso fazer uma "análise ascendente do poder"; quer dizer, ver como esses mecanismos foram investidos, colonizados, utilizados, transformados, por mecanismos cada mais gerais e por formas de dominação global. Por outro lado, não é necessário entender o poder como algo negativo, como uma forma de repressão, mas ver os seus efeitos positivos, isso que produz; não o entender como a dominação homogénea de um grupo, mas como presente em todo o sistema social ${ }^{38}$.

37 Habermas, "As ciências humanas desmascaradas pela crítica da razão: Foucault" in Der Philosophische Diskurs der Moderne. O discurso filosófico da modernidade, trad. Maria A. E. Soares, Lisboa, Publicações Dom Quixote, 1990, p. 239. Acerca da genealogia como estudo da "proveniência" e da "emergência", cf. Foucault, op. cit., pp. 1009-1011, pp. 1015-1016. Devemos ter cuidado em relação a esta persistência do poder. Pode dizer-se que em todas as épocas há relações de poder, tal como se pode dizer que em todas as épocas e em todas as sociedades há um sistema, um arquivo (cf. nota 26 deste estudo), mas são relações de poder e arquivos que mudam com a história. De "há sempre um sistema" não se concluirá que "o sistema é sempre o mesmo". Foucault afirma "para todos os tempos e sociedades, existem algumas (ou outras) relações e mecanismos de poder", mas de tal afirmação não se deve inferir, como alguns parecem fazer: "para algumas (e as mesmas) relações ou mecanismos de poder, essas relações ou mecanismos existem para todos os tempos e para todas as sociedades". O ênfase de Foucault no desenvolvimento histórico contradiz essa ilação. Como salienta Martin Kusch, inferir tal proposição é cometer a "falácia da composição" (cf. Martin Kusch, Foucault's Strata and Fields: An Investigation into Archaeological and Genealogical Science Studies, Dordrecht/Boston/ /London, Kluwer Academic Publishers, 1991, p. 219).

38 Acerca destas regras, temos em conta Surveiller et punir, edição citada, p. 31 e Foucault, "Il faut défendre la société», Paris, Gallimard/Seuil, 1997, pp. 25 ss. A recusa da "hipótese repressiva" é outro procedimento metódico com a sua dose de polémica. O poder não é essencialmente encobridor, é até condição de aparecimento: "Pour que quelque chose d'elles parvienne jusqu'à nous, il a fallu pourtant qu'un faisceau de lumière, un instant au moins, vienne les éclairer. [...] Toutes ces vies qui étaient destinées à passer au-dessous 
Se o arqueólogo considera enunciados em dispersão no campo do saber, tentando detectar regularidades, regras de formação, etc., o genealogista considera forças em dispersão no campo do poder-saber, tentando detectar estratégias, tácticas, relações:

"Por poder [...] é preciso compreender [...] a multiplicidade das relações de força que são imanentes ao domínio em que se exercem e que são constitutivas da sua organização; o jogo que, por via de lutas e confrontos incessantes, as transforma, reforça, inverte; os apoios que essas relações de força encontram umas nas outras, de maneira a formar encadeamento ou sistema $[\ldots]$ as estratégias nas quais tomam efeito $[\ldots]^{339}$.

Aos olhos do genealogista, o poder está em todo o lado, "vem de baixo", exerce-se, sempre com intenções e objectivos, a partir de pontos inumeráveis no jogo de relações desiguais e móveis. Nessa rede instável, o poder encontra pontos de resistência. Onde há poder, há resistência. As relações de poder só existem em função de uma multiplicidade de pontos de resistência presentes em toda a rede do poder. No entanto, face ao poder, não há algo como uma grande e "genérica" Recusa, mas resistências "específicas": resistências possíveis, necessárias, improváveis, espontâneas, selvagens, solitárias, concertadas, violentas, interessadas, etc. ${ }^{40}$.

Dada a sua omnipresença, não será de estranhar que o poder esteja presente no saber, no discurso. As relações de poder não estão numa posição de exterioridade face a outros tipos de relações (a relações de conhecimento, por exemplo); são imanentes a estas relações: são os efeitos imediatos de divisões, desigualdades e desequilíbrios que se produzem e são, reciprocamente, as condições internas dessas diferenciações ${ }^{41}$. Mas, nesse caso, objectar-se-á: não se passa à investigação das condições externas de possibilidade do discurso, não haverá uma confusão entre condições internas e externas?

Não. As relações de poder são condições internas das relações discursivas, não do discurso. Recuando a uma temática abordada em L'archéologie du savoir, diremos que o discurso existe sob as condições positivas de um feixe complexo de relações que são estabelecidas entre instituições, processos económicos e sociais, condutas, sistemas de normas, técnicas, etc. Essas condições não definem a constituição interna do discurso, mas permitem que seja colocado num campo de exterioridade. As relações discursivas não são nem internas, nem externas, ao discurso: estão no limite do discurso, caracterizam o próprio discurso enquanto prática ${ }^{42}$. Não será difícil compreender esse feixe de relações como relações de forças formando sistema segundo estratégias: como dispositivo.

de tout discours et à disparaître sans avoir été dites n'ont pu laisser de traces - brèves, incisives, énigmatiques souvent - qu'au point de leur contact instantané avec le pouvoir" (Foucault, "La vie des hommes infâmes" in Dits et écrits II, edição citada, pp. 240-241).

39 Foucault, Histoire de la sexualité I - La volonté de savoir, Paris, Gallimard, 1976, pp. 121-122.

40 Vide Foucault, op. cit., pp. 122-123, pp. 125-127.

41 Vide Foucault, op. cit., pp. 123-124.

42 Vide L'archéologie du savoir, edição citada, pp. 62-63. Segundo L'archéologie du savoir, esse campo de exterioridade é o do saber. Não é clara, aí, a distinção que Foucault estabelece entre as relações discursivas e as "relações primárias" que, independentemente do discurso, podem ser descritas entre instituições, técnicas sociais, etc. Ainda que diga, precisamente, que o problema é fazer aparecer a especificidade das relações discursivas e o seu jogo com as outras (cf. op. cit., p. 62). Portanto, L'archéologie du savoir estabelece a necessidade de considerar o discurso na sua autonomia, não ignorando a sua "heteronomia", o extradiscursivo. A genealogia analisa o "campo de exterioridade" como domínio das relações poder-saber. Digamos que analisa o discursivo enquanto articula e 
Também não será difícil entender o dispositivo como uma redefinição da positividade acima referida, como "matriz de transformação", como domínio de elementos heterogéneos: discursivos e extradiscursivos ${ }^{43}$.

Com a genealogia, a análise é amplificada: incide, não tanto na epistêmê, mas no dispositivo. A análise conserva, todavia, algumas características da arqueologia; por exemplo, continua situada no campo da história, o sujeito transcendental continua «suspenso», o discurso não deixa de ser visado:

“A genealogia é [...] uma forma de História que dá conta da constituição dos saberes, dos discursos, de domínios de objectos, etc., sem se referir a um sujeito, quer seja transcendente em relação ao campo de eventos, quer esteja em curso, na sua identidade vazia, ao longo de toda a história"44.

A arqueologia isola o nível das práticas discursivas e formula as suas regras de formação. A genealogia concentra-se nas forças e relações de poder conectadas com as práticas discursivas; não insiste na separação entre regras de formação do discurso e relações de poder. Arqueologia e genealogia são complementares. As análises das modalidades de poder, por mais precisas e detalhadas que sejam, não podem dar conta, por exemplo, das regras de formação do discurso médico nos séculos XVIII e XIX (cf. Naissance de la clinique); muitas destas regras, bem como as suas transformações, só são compreensíveis quando tomamos uma perspectiva interna ao desenvolvimento do saber médico. O nível das práticas discursivas deve manter a sua independência teórica, apesar de ser também necessário mostrar como se relacionam a técnicas e relações de poder. A arqueologia não sofre de um falhanço metodológico intrínseco, como alguns afirmam; é situada num horizonte de pesquisa mais lato, no qual o seu significado se transforma ${ }^{45}$.

é articulado por algo que não ele próprio. Contudo, note-se que Foucault sempre reconheceu regras de formação do saber independentes das relações entre saber e poder: "Puis, dès lors que le savoir scientifique a ses règles dont ne peuvent pas rendre compte les déterminations externes, mais bien sa structure propre comme pratique discursive [...]" (Foucault, "Préface à l'"Histoire de la sexualité»" in Dits et écrits II, edição citada, p. 1401).

43 Quanto à «matriz de transformação», cf. Histoire de la sexualité I, edição citada, p. 131, p. 139. Uma definição mais completa de «dispositivo» é fornecida em entrevista: "[...] c'est, [...] un ensemble résolument hétérogène, comportant des discours, des institutions, des aménagements architecturaux, des décisions réglementaires, des lois, des mesures administratives, des énoncés scientifiques, des propositions philosophiques, morales, philanthropiques, bref: du dit, aussi bien que du non-dit, voilá les éléments du dispositif. Le dispositif lui-même, c'est le réseau qu'on peut établir entre ces éléments. [...] ce que je voudrais repérer dans le dispositif, c'est justement la nature du lien qui peut exister entre ces éléments hétérogènes.[...] entre ces éléments, discursifs ou non, il y a comme un jeu, des changements de position, des modifications de fonctions [...] par dispositif, j'entends une sorte - disons - de formation, qui, à un moment historique donné, a eu pour fonction majeure de répondre à une urgence. Le dispositif a donc une fonction stratégique dominante" (Foucault, "Le jeu de Michel Foucault" in Dits et écrits II, edição citada, p. 299).

44 Foucault, "Entretien avec Michel Foucault" in Dits et écrits II, edição citada, p. 147.

45 No que diz respeito à complementaridade entre genealogia e arqueologia, seguimos a indicação de Arnold I. Davidson (cf. "Archaeology, Genealogy, Ethics" in David Couzens Hoy (Ed.), Foucault: a Critical Reader, New York, Basil Blackwell, 1986, pp. 227). Foucault tentou sempre conjugar essas vertentes da investigação. Referimos já, em nota, a pretensão de se dirigir para as condições externas de possibilidade do discurso, a partir do próprio discurso, da sua aparição e da sua regularidade, ou seja, a partir do trabalho 
Consideremos, agora, o aspecto crítico da genealogia.

Dissemos já que a crítica genealógica tem um carácter local. Este carácter indica também algo como uma produção teórica autónoma, não centralizada, que, para estabelecer a sua validade, não necessita do visto de um regime comum ${ }^{46}$. Isto leva a que se critique Foucault por não apresentar uma base normativa para o seu criticismo e também por não apresentar, face ao que critica, uma alternativa viável: "não critique, uma vez que nada tem a propor em alternativa".

A genealogia contempla o refugo do saber, saberes «sujeitados», hierarquicamente inferiores, abaixo do nível de conhecimento e cientificidade exigidos. Assume-se como uma "anti-ciência"; todavia, não se deduza que reivindique um direito lírico à ignorância ou ao não-saber: trata-se apenas da insurreição dos saberes. A genealogia não está contra os conteúdos, métodos ou conceitos das ciências, mas contra os efeitos centralizadores de poder que estão ligados à instituição e ao funcionamento de um discurso científico organizado no interior de uma sociedade como a nossa. É um empreendimento que tenta 'dessujeitar' os saberes históricos, torná-los capazes de oposição e luta contra a coerção de um discurso unitário, formal, científico. A genealogia luta contra a "epistemologização" crescente das formações discursivas que nos assombra desde a «Idade Clássica»:

"Chamem, se quiserem, "genealogia» a conexão dos conhecimentos eruditos e das memórias locais, conexão que permite a constituição de um saber histórico de lutas e o uso desse saber em tácticas actuais. [...] A arqueologia será o método próprio da análise das discursividades locais e a genealogia a táctica que faz entrar em jogo, a partir dessas discursividades locais assim descritas, os saberes dessujeitados que se libertam"47.

Como observámos já, a genealogia não prescinde da arqueologia. Pelo contrário, toma a arqueologia como método, instrumento ao serviço de uma filosofia crítica empenhada no presente: "a utilização desse saber nas tácticas actuais". A crítica pode agora enraizar-se no presente e elucidar as suas condições de possibilidade «extradiscursivas». A crítica genealógica exerce-se como um desses pontos de resistência a que aludimos acima: é possibilitada pelas relações entre poder e saber.

O discurso arqueológico-genealógico é um discurso de resistência, um ponto de resistência no dispositivo geral, na relação poder-saber. É que, de acordo com Foucault, há uma "polivalência táctica do discurso": o discurso veicula e produz poder, reforça-o, mas pode também miná-lo, expô-lo, torná-lo frágil, pode ser obstáculo, ponto de resistência, partida para uma estratégia oposta. Os discursos são elementos ou blocos tácticos no campo das relações de força ${ }^{48}$.

A genealogia, enquanto resistência, adopta uma postura crítica face ao poder da ciência na sociedade moderna, não face à produção científica enquanto tal (na sua

especificamente arqueológico (cf. L'ordre du discours, edição citada, p. 55, e pp. 67-69; acerca desta conjugação, veja-se também "Il faut défendre la société», edição citada, pp. 11-12 e Histoire de la sexualité II, edição citada, p. 19).

46 Vide Foucault, "Il faut défendre la société», edição citada, p. 8.

47 Foucault, "Il faut défendre la société», edição citada, pp. 9-12. Sobre a 'epistemologização', cf. L'archéologie du savoir, edição citada, p. 255.

48 Acerca da "polivalência táctica do discurso", cf. Histoire de la sexualité I, edição citada, p. 133. 
autonomia, digamos). A contribuição específica da genealogia não consiste na crítica de instituições ou pessoas, mas, a partir da análise, identificação e descrição de dispositivos de saber-poder que tornam possiveis e justificam certas instituições ou estratégias, em tornar criticáveis esses mesmos dispositivos ou padrões de racionalidade nos quais certas instituições e estratégias se justificam para serem aceites como razoáveis, úteis, evidentes, e a partir dos quais a violência dessas instituições e estratégias se pode tornar natural e justificável. O que a genealogia procura mostrar é que apesar de certas instituições ou estratégias serem defensáveis, dados os princípios historicamente contingentes e os dispositivos locais que os sustentam, essas mesmas instituições e estratégias são apenas defensáveis dados esses princípios historicamente contingentes e os dispositivos locais que os sustentam. O que se procura esclarecer é a contingência, o relativismo, dos padrões daqueles que vêem o sistema presente como suficiente e defensável ${ }^{49}$.

Os dispositivos não são questionados a partir de um ponto além de todos eles o que manifesta uma clara diferença relativamente à arqueologia. A genealogia é contra certos saberes (por extensão, contra a razão), mas não está situada fora da razão. Está com a razão contra a razão. É crítica interna à própria razão, é saber que mina o próprio saber, ponto de resistência, insurreição, agitação:

"Não podendo operar senão no interior da razão, uma vez que se profere, a revolução contra a razão tem sempre, pois, a extensão limitada do que se chama, justamente na linguagem do ministério do interior, uma agitação"s0.

O que se pretende é, do interior, mostrar que as alternativas a certos dispositivos são possíveis. Mostrar a sua contingência, contestar a sua necessidade, é já um passo nessa direcção. Esse é o único e decisivo passo dado pela genealogia, uma vez que é sem catecismos, breviários, "regras para a direcção do espírito". Podemos modificar os dispositivos ao questioná-los como dispositivos meramente locais dentro do dispositivo mais geral da nossa cultura, dispositivo que se modifica com a história. Admitir a necessidade, a universalidade, desses dispositivos é negar a historicidade desses mesmos dispositivos, divorciá-los da actualidade. Mostrar a sua contingência é abrir caminho para um sempre possível "pensar de outra maneira".

Inevitavelmente, a genealogia deve mostrar que as resistências e as alternativas não são só possíveis, mas necessárias, melhores; quer dizer, deve justificar a sua posição. A genealogia não é neutra como a arqueologia, é orientada por "interesses". Teremos de ver, pois, qual a razão da luta, da resistência.

\section{A ontologia do presente}

Para Foucault, o problema filosófico essencial da nossa época, a grande tarefa filosófica actual, é a análise crítica do mundo em que vivemos. A filosofia é "ontologia do presente", pergunta: quem somos nós? Quem somos nós neste preciso momento da história?" "Ontologia do presente" que se perfaz enquanto "ontologia histórica" ou "história crítica do pensamento". A ontologia histórica pesquisa, na sua tripla raiz, a

A este propósito consultar-se-á com proveito o estudo de Martin Kusch (cf. Martin Kusch, op. cit., p. 214 ss).

so Derrida, "Cogito et histoire de la folie" in L'écriture et la différence, Paris, Éditions du Seuil, 1967, p. 59.

sI Vide "Le sujet et le pouvoir" in Dits et écrits II, edição citada, p. 1051. 
formação, o desenvolvimento e a transformação de experiências do pensamento. Por pensamento entende-se o que instaura, em diversas formas possíveis, o jogo do verdadeiro e do falso e constitui o ser humano como sujeito de conhecimento; o que funda a aceitação ou recusa da regra e constitui o ser humano como sujeito social e jurídico; o que instaura o ser humano consigo próprio e com os outros e constitui o ser humano como sujeito ético. Para Foucault, o pensamento não deve ser investigado apenas em formulações teóricas, mas também nas maneiras de dizer, de fazer, de se conduzir, em que o indivíduo se manifesta e age como sujeito de conhecimento, como sujeito ético ou jurídico, como sujeito consciente de si e de outros. A ontologia histórica analisa as problematizações e as práticas que constituem a experiência histórica disso "que pode e deve ser pensado"; por experiência, entende-se a correlação, numa cultura, entre domínios de saber, tipos de normatividade e formas de subjectividade. O pensamento tem uma historicidade própria e a filosofia crítica, entendida como análise das condições históricas segundo as quais se constituem as relações à verdade, à regra e ao si, deve esclarecer as suas transformações. A filosofia crítica é um trabalho do pensamento sobre si próprio: deve investigar como é possivel que o pensamento tenha uma história e deve ver como se produziram as diversas formas do pensamento, os aspectos concretos que puderam tomar na história ${ }^{52}$.

A ontologia histórica é uma luta e o objectivo principal não é descobrir quem somos: é recusar o que (ou quem) somos, recusar o tipo de individualidade que nos impuseram durante séculos, promover novas formas de subjectividade ${ }^{53}$. Essa é a finalidade da filosofia crítica. A (re)aproximação a Kant clarificará este aspecto.

$* * *$

Segundo Foucault, a tarefa filosófica a que aludimos começou por ser proposta no opúsculo de Kant que responde à questão "o que é o Iluminismo?". Mais, toda a filosofia moderna tenta responder a tal questão.

Esse pequeno texto constitui-se, em Kant, como ponto de união entre a reflexão crítica $e$ a reflexão sobre a história; ponto que mostra também a "proveniência" da filosofia de Foucault, entrincheirada nessa junção. A novidade do opúsculo parece ser a reflexão sobre a actualidade, sobre o momento presente visto como diferença na história e como motivo para uma tarefa filosófica. É verdade que Kant situa essa actualidade no movimento de passagem da humanidade ao seu estádio de maioridade, o ponto para o qual caminha a história (o seu «a priori histórico»); mas, ao mesmo tempo, mostra como, nesse momento actual, cada um é responsável pelo processo colectivo. O que se esboça é aquilo que se pode chamar a "atitude de modernidade". Atitude entendida como modo de relação à actualidade, como escolha voluntária, como maneira de pensar, sentir, agir; em grego: um êthos ${ }^{54}$.

Foucault sublinha o enraizamento, no Iluminismo, de um tipo de interrogação filosófica que problematiza simultaneamente a relação ao presente, o modo de ser histórico e a constituição de si mesmo como sujeito autónomo. Contudo, a aproximação ao Iluminismo não é elaborada segunda uma fidelidade ou infidelidade a elementos de

52 Vide "Préface à l' «Histoire de la sexualité» in Dits et écrits II, edição citada, pp. 1398-1400 e Histoire de la sexualité II, edição citada, p. 10 e p. 19.

53 Vide "Le sujet et le pouvoir", edição citada, p. 1051.

54 Vide "Qu'est-ce que les Lumières?" in Dits et écrits II, edição citada, p. 1386 ss. Sobre o estranho "a priori histórico» kantiano, cf. "Idee zu einer allgemeinen Geschichte in weltbürgerlicher Absicht". "Idea for a universal history with a cosmopolitan purpose" in Kant: Political Writings, trad. H. B. Nisbet, Cambridge, Cambridge University Press, 2001, p. 53. 
doutrina; deve evitar-se a "chantagem intelectual e política da Aufklärung", o "a favor ou contra", a dicotomia "racionalista-irracionalista". O que interessa antes de mais é a reactivação permanente de um êthos filosófico que pode ser caracterizado como crítica e criação permanentes do nosso ser histórico, de nós próprios, na nossa autonomia.

A ontologia crítica implica uma série de investigações históricas, investigações que não se orientam retrospectivamente para o "núcleo essencial da racionalidade" que teríamos a tudo o custo de salvar, mas orientadas para os "limites actuais do necessário", para o que não é, ou já não é, indispensável à constituição de nós próprios como sujeitos autónomos; quer dizer, para o contingente. A crítica é análise dos limites e reflexão sobre estes. Todavia, a questão crítica não deve ser negativa como a de Kant, que procurava saber que limites o conhecimento não devia transpor, mas positiva: no que nos é dado como universal, necessário, obrigatório, que lugar tem o que é singular, contingente ou resultado de constrangimentos arbitrários? E preciso transformar a crítica exercida na forma de limites necessários numa crítica prática na forma da transgressão possível: "transgride de tal maneira que a tua transgressão se torne ao mesmo tempo um novo limite (ele mesmo passível de transgressão futura)". A filosofia crítica exerce-se não já como investigação das estruturas formais que têm valor universal, mas como investigação histórica dos eventos que nos levam a constituir-nos, reconhecer-nos, como sujeitos do que fazemos, pensamos, dizemos. A filosofia crítica não é mais transcendental: é genealógica na sua finalidade e arqueológica no seu método. Arqueológica, e não transcendental, porque não procura destacar as estruturas universais de todo o conhecimento ou de toda a acção moral possível: procura tratar os discursos que articulam o que pensamos, dizemos e fazemos como se fossem eventos históricos. Será genealógica porque não deduz da forma do que somos o que nos é impossível fazer ou conhecer, mas destaca da contingência que nos fez ser o que somos, fazemos ou pensamos, a possibilidade que temos de não mais o ser, fazer ou pensar ${ }^{55}$.

A ontologia crítica de nós próprios não é uma teoria ou doutrina. É uma atitude que deve passar pela experiência da realidade e da actualidade, para que possa apreender os pontos em que a mudança, a resistência, é possível, desejável, e aqueles em que não é necessária (há formas hegemónicas de poder a que devemos resistir, mas há também formas - não hegemónicas - de poder a que não precisamos resistir). As mudanças e as resistências são pequenas, parciais, locais. A ontologia histórica não é um projecto global, radical, é limitada, determinada e sempre passível de recomeço. O que se propõe é um êthos, uma vida filosófica em que a crítica do que somos é análise histórica dos limites que nos são colocados e experiência da sua transgressão possível. Vida que procura promover e dar forma à impaciência da liberdade segundo o princípio da autonomia ${ }^{56}$.

Entre renúncia e fidelidade, a filosofia crítica é redefinida:

"Mas o que é hoje a filosofia [...] senão o trabalho crítico do pensamento sobre si mesmo? E se ela consiste, não em legitimar o que já se sabe, mas em tentar saber como e até onde será possível pensar de outra maneira? [...] um exercício filosófico [...] é tentar saber em que medida o trabalho de pensar a sua própria história pode libertar o pensamento do que pensa silenciosamente e permitir-lhe pensar de outra maneira" ${ }^{57}$. 


\section{Algumas conclusões}

Arqueologia e.genealogia são dimensões complementares de uma mesma filosofia crítica interessada na actualidade. A arqueologia, ao analisar as transformações históricas do saber, providencia à genealogia marcas que indicam o caminho que deverá cartografar de modo a dar conta de como foi possível chegarmos contingentemente a ser quem somos. A arqueologia é a dimensão teórica, neutra, da crítica; se se quer mostrar o passado enquanto passado, considerar a diferença do nosso presente, importa dirigir-se ao passado de um modo neutro; caso contrário, não se escapa à «fusão de horizontes» e o presente não é diferença. A genealogia é a dimensão prática, interessada, da crítica; ao revelar a contingência do que somos, a genealogia abre um espaço no qual nos podemos compreender-nos como outros do que somos, como podendo ser diferentes.

Esse trabalho tem uma finalidade e uma justificação. A condição de possibilidade da genealogia é a resistência. Como vimos, a possibilidade da resistência é condição de possibilidade do exercício do poder e o exercício da resistência ao poder relança o trabalho da liberdade. Há uma relação intrínseca entre a genealogia e a resistência que se expressa quer na ideia de genealogia, na medida em que se preocupa em mostrar como o que somos implica também a possibilidade de sermos diferentes do que somos, quer na prática da genealogia, como uma investigação de como podemos ser diferentes do que somos. A genealogia é um exercício de resistência "impaciente de liberdade" orientado por um princípio, valor ou interesse: a autonomia. A genealogia é um exercício crítico de resistência que promove, articula, exerce e procura manter aberta a possibilidade da autonomia. A autonomia constitui-se através da actividade da luta, da crítica permanente de nós próprios, pela qual nos criamos $^{58}$.

Com a redefinição da filosofia crítica, enquanto arqueologia $e$ genealogia, notamos a fusão das tarefas dos dois tipos de filósofo que referimos na introdução : fazer filosofia é estudar o espaço em que se desdobra o pensamento $e$ abrir a possibilidade de "pensar de outro modo", é reflexão crítica $e$ reflexão sobre a história, é atentar (em todos os sentidos do verbo) o presente, a actualidade. A filosofia é uma prática, uma actividade entre o limite e a transgressão, entre movimentos: entre um passado que não está ainda fechado, mas a fechar-se, e um futuro que não está ainda aberto, mas a abrir-se. Auxiliando-nos com as palavras do filósofo que mais justiça fez a Foucault, digamos que a sua filosofia crítica está entre a história e o actual, entre o arquivo e o esboço do que podemos ser:

"Em todo o dispositivo, devemos destrinçar as linhas do passado recente e as do futuro próximo: a partedo arquivo e a do actual, a parte da história e a do devir, a parte da analítica e a do diagnóstico. Se Foucault é um grande filósofo, é porque se serviu da história em proveito de outra coisa: [...] agir contra o tempo e, assim, sobre o tempo, a favor, espero, de um tempo por vir. [...] Não predizer, mas estar atento ao desconhecido que bate à porta" 59 .

Sobre a relação entre genealogia, resistência e autonomia em Foucault, cf. David Owen, op. cit., p. 161 ss., p. 208 ss.

59 Deleuze, "Qu'est-ce qu'un dispositif?" in Michel Foucault Philosophe, Paris, Éditions du Seuil, 1989, pp. 190-191. 
Fílosofia "votada ao fluxo do tempo" que "pensa a sua própria história" (passado) para se libertar "do que pensa silenciosamente"(presente) e poder "pensar de outra maneira" (futuro). A filosofia de Foucault pensa a sua própria história, tem a sua "tradição". Ainda que se oriente para o passo em frente, não ignora nem o "passo atrás", nem os "passos em volta". Em relação à tradição, lembramos a disjunção adiantada por Husserl: ou os valores tradicionais são completamente rejeitados ou o seu conteúdo é objecto de uma renovação e recebe uma nova forma no espírito da idealidade filosófica ${ }^{60}$. Pensamos que Foucault subscreve a segunda disjunta: renuncia e mantém-se fiel a uma certa tradição.

Tal como outros, Foucault não desejava começar, queria ser precedido por um amigo, como se este lhe dissesse: "É preciso continuar, eu não posso continuar, é preciso continuar...". Era em direcção a uma falta, onde provava a ausência e os seus próprios defeitos, que se cruzavam as questões que colocava. Sabia bem que amigo o precedia, conduzia e convidava a falar, e que se alojava de alguma maneira no seu próprio discurso. Sabia o que havia de tão temível em tomar a palavra, porque a tomava no lugar onde tinha escutado esse amigo e onde ele não mais estava para o escutar ${ }^{61}$. 
